\title{
The view from the Rock
}

Published at www.cmaj.ca on Aug. 27

I $t$ is not uncommon for natives of Newfoundland and Labrador to argue that people get a unique perspective on life's challenges from living on a rock.

If Canadian Medical Association President-Elect Dr. John Haggie is any indicator, there may be a great deal of truth to that proposition.

Lively, quick-witted, possessed of a curious twist of mind and an even more devious sense of humour, the general/vascular surgeon and chief of staff at the James Paton Memorial Hospital in Gander, Newfoundland and Labrador, is nothing if not thought-provoking.

He shifts seamlessly from topic to topic, from the "holes in medicare" to the challenges faced by small-town rural doctors, almost within the span of a single sentence.

Asked, for example, to explain what he meant when he once asserted that drugs are the defining modality of modern medical management, Haggie delivers a quasi-historical dissertation on the evolution of medicare in Canada.

"If you look at current medicare, we're not allowed to hint that we want to touch it because it's become so iconic," he responds. "Politicians regard it as the sort of 'live' third rail kind of thing. They just don't want to go near it. But, honestly, it was designed and implemented in the 1980s with approaches to health care that really were rooted in the $50 \mathrm{~s}$ and $60 \mathrm{~s}$, a generation before. And at that time, by and large, people were acutely ill and managed in hospitals and then convalesced at home."

"The problem we've got now is that there's so much more chronic disease management, while the level of technology and management and expertise for managing surgical issues, which is sort of my bread and butter, has changed, so you can do most of it as day cases."

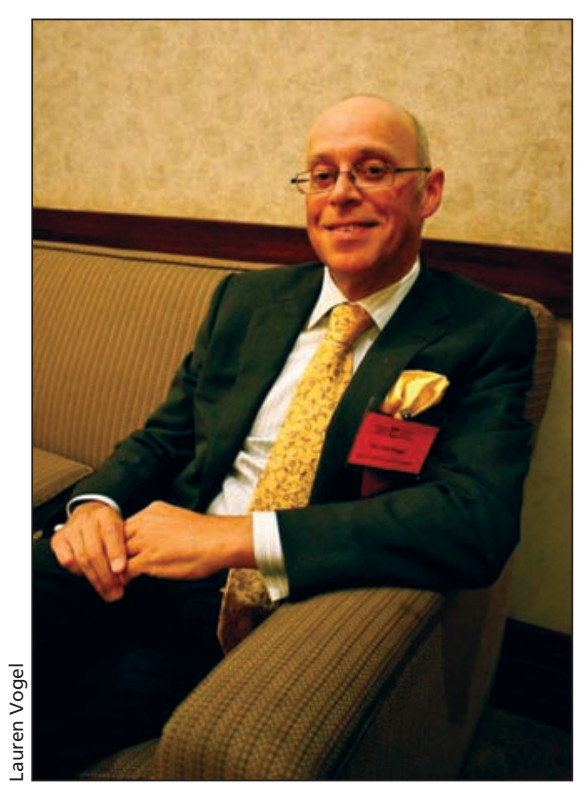

"Now the big holes are in community care, and end-of-life care and care of the elderly. Those were never considered by medicare. The challenge is how to fill those gaps," says CMA PresidentElect Dr. John Haggie.

Yet with that transition from a system based on hospitals and in-patient care, "holes have appeared because of the change in emphasis in health care, with wellness and prevention and vaccination. We don't have pediatric wards with 30 children on them any more in small rural communities (as was the case when Haggie migrated from England to take a consulting surgeon's position with Grenfell Regional Health Services in St. Anthony, Newfoundland and Labrador)."

"Now the big holes are in community care, and end-of-life care and care of the elderly. Those were never considered by medicare. The challenge is how to fill those gaps. I mean, if you have a chest infection, you get a cough, you go to your doctor. The system will pay for that clinical visit ... If you need a chest x-ray, you get it. You don't pay. And then you get a prescription for a very good antibiotic which will cost you \$250."
Therein lies the new modality, and a harsh reality.

"In Newfoundland," Haggie concludes in response, "the average yearly income is less than $\$ 30000$ per year. So if you work in Newfoundland, you are actually 'working poor.' And you are probably not making enough to pay" for either drug insurance or the $\$ 250$ antibiotic.

"I see that on a regular basis. I don't think that is isolated. I think that's a general national problem. It's also a big issue: how to deal with a population that is increasingly less able to care for themselves and living longer."

Haggie is no less intriguing on the challenges of small town practice, from the difficulty of being a "solo practitioner," to the complexities of having to juggle travel to larger cities to access continuing medical education programs on new surgical techniques.

He laces his descriptions of such obstacles with tales of the joys of small-town life, weaving challenges and charms into a seamless story, from the difficulty of arranging an anesthetist for a surgery to the unexpected surprise of having a school bus driver scoot extra miles to deliver a daughter's homework inadvertently left on a seat. "You can't put a price on that."

A graduate of the Victoria University of Manchester School of Medicine, Haggie says he chose medicine as a profession when as a biology student at William Hulme's Grammar School, he was "intrigued as to what made people tick. And I thought, being a very simplistic youth at the time, that perhaps, if I could cut them open I'd find out what it was, so I went and did surgery. I mean, you look at the machinery inside the box to see if that helps. ... I guess for a biology student, the logic was either dentistry or medicine, and teeth seemed a bit narrow."

Haggie immigrated to Canada in 1993 for an array of reasons, including disaffection with the Conservative government that was unveiling magic bul- 
lets for the National Health Service "that would change every week."

President of the Newfoundland and Labrador Medical Association in 200203 , when the association conducted a 17-day work action that eventually yielded a $\$ 54$ million increase in the annual medical services budget, Haggie served on the CMA board of directors from 2006-2009 and is currently chair of the CMA Ad Hoc Working Group on Pharmaceutical Issues.

As the man who'll assume the mantle of champion of the CMA's transformation agenda when he takes the reins from Dr. Jeff Turnbull in August, 2011, Haggie calls the blueprint an "innovative" approach to health care reform.
“"'Jeff's idea of turning it around and looking at it from the patient's point of view is probably the best way of doing it. It's an approach that hasn't been tried. Really and honestly, we've tried every other lens to look at health care. The politicians have looked at it with the money. The surgeons have looked at it from the point of view of 'what's the latest, greatest toys'. The internists are after it for the latest and greatest in drug therapy. So let's try and see what it looks like from the end-user point of view and look at it as a spectrum. What do I need as two-month-old? What do I need as a 20-year-old woman? What do I need as a 40-year-old man? An 80-year-old lady?"

A recent convert to cottaging, Haggie and wife Peggy Champion are dis- covering the unique pleasures of fixing water pipes, installing solar power arrays and wielding a chainsaw at a tree. It's his latest hobby, having "grounded himself" and given up his commercial pilot's licence because of problems with his vision. The couple have five children, Hollie, Jennifer, Elizabeth, Justin and Claire, and one grandson, Lincoln.

"And I love snowmobiling. That's one of the things about the Rock. You give me a decent winter, 600 centimetres of snow, marvelous. I have a thing about internal combustion engines. If it's got an internal engine in it, I'll probably buy it." — Wayne Kondro, CMAJ

DOI:10.1503/cmaj.109-3358 